\title{
Change in tropical forest cover of Southeast Asia from 1990 to 2010
}

\author{
H.-J. Stibig ${ }^{1}$, F. Achard ${ }^{1}$, S. Carboni ${ }^{2}$, R. Raši ${ }^{1,3}$, and J. Miettinen ${ }^{1}$ \\ ${ }^{1}$ Joint Research Centre of the European Commission, Institute for Environment and Sustainability, TP 440, 21027 Ispra (VA), \\ Italy \\ ${ }^{2}$ Engineering SpA, Joint Research Centre of the European Commission, Institute for Environment and Sustainability, TP 440, \\ 21027 Ispra (VA), Italy \\ ${ }^{3}$ National Forest Centre, Forest Research Institute, 96092 Zvolen, Slovak Republic \\ Correspondence to: H.-J. Stibig (hans-juergen.stibig@jrc.ec.europa.eu)
}

Received: 4 July 2013 - Published in Biogeosciences Discuss.: 5 August 2013

Revised: 19 November 2013 - Accepted: 28 November 2013 - Published: 22 January 2014

\begin{abstract}
The study assesses the extent and trends of forest cover in Southeast Asia for the periods 1990-2000 and 2000-2010 and provides an overview on the main causes of forest cover change. A systematic sample of 418 sites $(10 \mathrm{~km} \times 10 \mathrm{~km}$ size $)$ located at the one-degree geographical confluence points and covered with satellite imagery of $30 \mathrm{~m}$ resolution is used for the assessment. Techniques of image segmentation and automated classification are combined with visual satellite image interpretation and quality control, involving forestry experts from Southeast Asian countries. The accuracy of our results is assessed through an independent consistency assessment, performed from a subsample of 1572 mapping units and resulting in an overall agreement of $>85 \%$ for the general differentiation of forest cover versus non-forest cover. The total forest cover of Southeast Asia is estimated at $268 \mathrm{Mha}$ in 1990 , dropping to $236 \mathrm{Mha}$ in 2010 , with annual change rates of $1.75 \mathrm{Mha}(\sim 0.67 \%)$ and 1.45 Mha $(\sim 0.59 \%)$ for the periods $1990-2000$ and 2000 2010 , respectively. The vast majority of forest cover loss $(\sim 2 / 3$ for $2000-2010)$ occurred in insular Southeast Asia. Complementing our quantitative results by indicative information on patterns and on processes of forest change, obtained from the screening of satellite imagery and through expert consultation, respectively, confirms the conversion of forest to cash crops plantations (including oil palm) as the main cause of forest loss in Southeast Asia. Logging and the replacement of natural forests by forest plantations are two further important change processes in the region.
\end{abstract}

\section{Introduction}

About $15 \%$ of the world's tropical forests are located in Southeast Asia (FAO, 1995), including for this study Papua New Guinea (PNG) and the Solomon Islands as part of the Southeast Asia region (Fig. 1). Forests in continental Southeast Asia consist for the most part of mixed deciduous forest types, including for instance the precious Teak forests, whilst the insular sub-region holds for example large extents of highly productive evergreen Dipterocarpus forests. Carbonrich ecosystems of mangrove and peat swamp forests still occupy many coastal zones of the region (Donato et al., 2011; Page et al., 2011). Southeast Asia's tropical forests play an important role for environmental protection and biodiversity, as well as for socio-economy and the living conditions of forest-dependent populations (e.g. Lee, 2009). These forests are also of importance in the context of global carbon balance. Deforestation in the tropics is considered to contribute about $15 \%$ of man-made global emissions (van der Werf et al., 2009), and the deforestation rate in Southeast Asia has been among the highest in the tropics (e.g. Achard et al., 2002). The United Nations Food and Agriculture Organisation (FAO) reported a net annual forest area loss in Southeast Asia of 2.4 Mha in the 1990s, and then of 0.4 Mha and 1.0 Mha for the periods 2000-2005 and 2005-2010, respectively (FAO, 2010).

However, estimates of tropical forest area and change still contain considerable uncertainty, impeding the estimation of carbon emissions caused by deforestation and forest degradation in the tropics (e.g. Harris et al., 2012). At regional levels, forest cover estimates derived by aggregation of national 


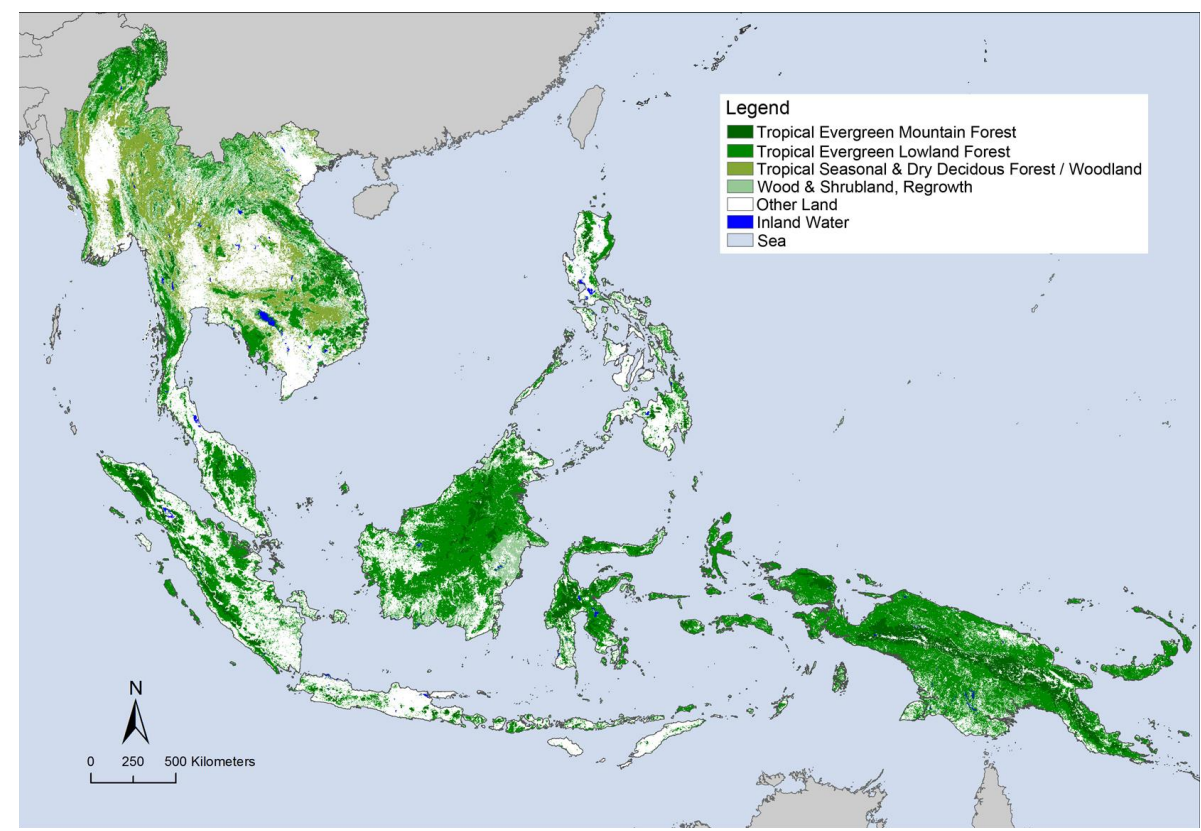

Fig. 1. Regional extent of tropical forest in Southeast Asia (incl. Papua New Guinea) derived from SPOT VEGETATION 1km data of the year 2000 (Stibig et al., 2007a).

forest data (e.g. FAO, 2010) are often affected by incompatibilities of the individual inventory methodologies, definitions and inventory dates. There is notable variability between forest change estimates also at national levels. For example, for Indonesia the annual loss of "forest land" for the periods 2000-2005 and 2005-2010 has been reported by FAO (2010) at about $0.3 \mathrm{Mha}$ and $0.7 \mathrm{Mha}$, respectively. Recent remote sensing studies estimated annual change in "forest cover" at about 0.7 Mha and 0.9 Mha for the periods 2000-2005 and 2000-2010, respectively (Hansen et al., 2009; Miettinen et al., 2011). The call to reduce uncertainties in estimating change in tropical forest cover is also driven by the reporting needs in the context of a potential mechanism of "Reducing Emissions from Deforestation and Degradation" (REDD+) (e.g. Bucki et al., 2012).

The objective of this study is to provide a uniform assessment of forest cover and forest cover change in Southeast Asia for the periods 1990-2000 and 2000-2010. We aim at a regional perspective, consistent across country boundaries and through the study period, linking to the main causes of forest change. The results are expected to serve as a reference at regional scale, for example as input to regional emission scenarios, but they can also be of interest for cross-boundary concepts of forest conservation, protected area networking or watershed management. The study has been implemented in the context of the Global Forest Resources Monitoring activity (TREES-3) of the Joint Research Centre, analysing a systematic pan-tropical sample of more than 4000 sites through the use of satellite imagery of medium spatial resolution. The activity also contributes to the Remote Sensing Survey of the
FAO Forest Resources Assessment 2010 (FRA-2010) Project (FAO and JRC, 2012).

\section{Materials and methods}

\subsection{Sampling, image processing, automated classification and visual review}

The TREES-3 sample over Southeast Asia comprises 418 sample sites, of which 161 sites are located in continental Southeast Asia (Cambodia, Laos, Myanmar, Thailand and Vietnam) and 257 in insular Southeast Asia (Brunei, East Timor, Indonesia, Malaysia and the Philippines, in addition PNG and the Solomons). The sample units, each covering an area of $10 \mathrm{~km} \times 10 \mathrm{~km}$, are systematically placed at each integer confluence of the geographic grid and cover in total about $1 \%$ of the total land area. Although stratified sampling might have offered higher efficiency for a single assessment, the choice for a systematic sampling grid has been made to allow for easy, strata-independent follow-up assessments and for direct nesting to national forest inventories, which are in most tropical countries based on systematic sampling designs (Mayaux et al., 2005; FAO and JRC, 2012). For all sample units satellite imagery from optical sensors at medium resolution (i.e. circa $30 \mathrm{~m}$ ) has been selected as close as possible to the reference years 1990, 2000 and 2010. Great effort has been made to establish an optimal image database, obtaining acquisitions of best quality for individual locations, and accounting particularly in continental Southeast Asia for vegetation seasonality (Beuchle et al., 2011). The vast majority of 
imagery was obtained from the Landsat TM/ETM+ archive of the US Geological Survey (USGS, 2013). For the year 2010 imagery from other optical sensors was included in the database (Table 1). The satellite data was pre-processed including radiometric calibration, de-hazing, spectral normalization and cloud-masking (Bodart et al., 2011). A multistage and multi-date image segmentation algorithm was applied, creating spatially and spectrally consistent mapping units (polygons) with a stable minimum mapping unit (5 ha) and a unit size of about 40 ha in average (Raši et al., 2011). A preliminary labelling of the mapping units was performed by automated supervised classification. For the years 1990 and 2000 the classification was based on the spectral signatures of 73 initial land cover types, which were grouped to a few main land cover classes (Raši et al., 2011). For the automated labelling of the 2010 mapping units, the spectral training signatures of the main land cover classes were established for each sample unit from the year 2000 classification results. Then a minimum distance change detection procedure was applied to the spectral signatures of the 2010 polygons. Polygons detected as "changed" between 2000 and 2010 were labelled for the year 2010 according to the training signatures, whilst all other 2010 mapping polygons were labelled identical to those of the year 2000 (Raši et al., 2013). This largely automated phase was followed by an intense phase of visual review and adjustment of the mapping results, with the following objectives: (i) correcting labelling errors of the automated classification procedure, (ii) ensuring a consistent and interdependent mapping for the three dates, and (iii) integrating the forest knowledge from tropical forestry experts through a series of workshops. The importance of the visual-manual component is reflected by the fact that for example for the 1990-2000 classification about $20 \%$ of the automatically pre-labelled polygons were re-coded after visual control (Raši et al., 2011). As reference for visual review and correction we made intense use of high-resolution satellite imagery from the TROPFOREST project (ESA, 2013) as well as from Google Earth ${ }^{\odot}$. For the region of interest TROPFOREST acquired 328 ALOS-AVNIR (10 m resolution) and 81 KOMPSAT ( $4 \mathrm{~m} / 1 \mathrm{~m}$ resolution) images, most of them from the year 2010, some also from 2011. ALOS PALSAR mosaics (50 m resolution) from the year 2008 (ALOS, 2010) were used to support the differentiation between forest cover and oil palm plantations (e.g. Miettinen and Liew, 2011).

\subsection{Land cover categories and area estimation}

Our study focused on the assessment of forest and other woody vegetation cover, particularly on the land cover classes "Tree Cover" (TC), "Tree Cover Mosaic" (TCM) and "Other Wooded Land" (OWL) (Fig. 2). TC and TCM were defined as land cover units containing a tree cover portion of $>70 \%$ and $30-70 \%$, respectively. We adopted a "tree cover" definition compatible to the FAO "forest" definition in terms of canopy density $(\geq 10 \%)$ and tree height $(\geq 5 \mathrm{~m})$. Con- trary to the FAO forest definition we did not account for aspects of dominant land use or potential tree growth. Our tree cover therefore includes natural forests, mature forest plantations as well as tree cover outside forest lands. All other woody vegetation was assigned to OWL (height $<5 \mathrm{~m}$ ), including shrubs, re-growth, forest plantations in initial growth stages, as well as oil palm plantations. All non-woody land cover was grouped into the category "Other Land" (OL), except for inland water bodies (WA). We also increased the minimum size criterion to 5 ha (FAO 0.5 ha), given the pantropical scale of the study and the limitations set by the spatial resolution of Landsat imagery.

It should be noted that the criteria on minimum canopy density and tree height could be used as guideline, but not in the sense of rigorous measures. From Landsat imagery neither the $10 \%$ tree-cover threshold nor the $5 \mathrm{~m}$ height threshold can be precisely determined. The separation of forest and non-forest therefore had to be done in "approximation" to these thresholds. However, the vast majority of forest canopies in Southeast Asia have densities notably higher than $10 \%$, and in cases of very open tree cover (e.g. heavily degraded or dry deciduous tree cover) we could refer to a large number of high-resolution reference imagery to support the class assignment. Referring to tree height, the differentiation between tree cover above and below the height threshold could only be approximately deduced from the spectral response and textural pattern of tree canopies.

We calculate land cover proportions for each sample unit and estimate the total area of land cover change using the Horovitz-Thomson Direct Expansion Estimator (Eva et al., 2012; Supplement). Land cover areas are linearly adjusted by site to the baseline dates of 30th June of each reference year and then expressed as percentages of the total unit land area, excluding "sea", "clouds" and "no-data" (i.e. proportions over total). For three missing sites (i.e. no imagery available) area estimates are inferred from the weighted average obtained from their eight closest neighbouring sample sites. In the estimation phase, the sample units are weighted with the co-sinus of the corresponding latitude to compensate for increasing sampling probability at higher latitudes (convergence of meridians). The land cover area estimates at sub-regional and regional levels are then calculated by multiplying the average weighted proportions for all sample sites with the appropriate land area of a given region. Regional land areas are obtained from the spatial data set "Country Boundaries of the World" (FAO, 2007). The areas of the categories "TC" and "TCM" are counted as $100 \%$ and $50 \%$ forest cover, respectively. Change rates in forest cover are calculated in relation to the averaged forest areas between the beginning and end of each assessment period, e.g. average of forest areas in 2000 and 2010 for the change rates 2000-2010. For each area estimate, the corresponding standard error (se) is given in absolute terms based on the local estimation of the variance. 
Table 1. Use of satellite imagery for sample sites in Southeast Asia.

\begin{tabular}{lrrrrrrrr}
\hline Satellite Sensor & TM & ETM & SPOT HRV & ASTER & ALOS AVNIR & KOMPSAT & DEIMOS & RAPID EYE \\
\hline (Spatial Resolution) & $(30 \mathrm{~m})$ & $(30 \mathrm{~m})$ & $(20 \mathrm{~m})$ & $(15 \mathrm{~m})$ & $(10 \mathrm{~m})$ & $\left(20 \mathrm{~m}^{*}\right)$ & $(22 \mathrm{~m})$ & $\left(10 \mathrm{~m}^{*}\right)$ \\
Year & - & - & - & - & - & - & - & - \\
1990 & 408 & - & 8 & - & - & - & - \\
2000 & 4 & 410 & 2 & - & - & - & - \\
2010 & 302 & 69 & - & 1 & 33 & 1 & 1 \\
\hline
\end{tabular}

* resampled.

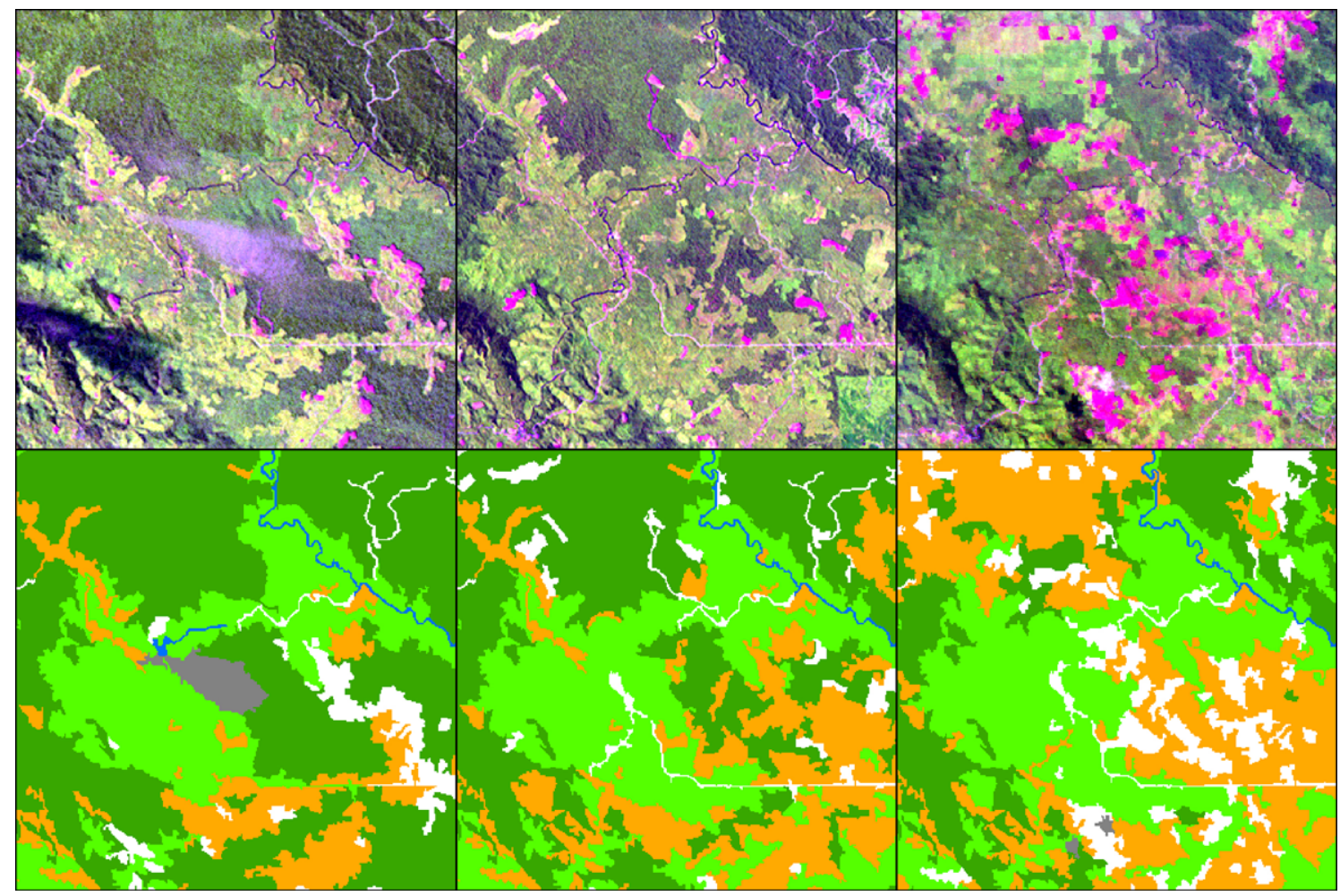

Fig. 2. Example of image and mapping results for a sample site $(10 \mathrm{~km} \times 10 \mathrm{~km})$ on Borneo $\left(0^{\circ} \mathrm{N}, 101^{\circ}\right)$. (top panels) Landsat $\mathrm{TM}$ and ETM+ satellite imagery for reference years 1990 (left), 2000 (middle) and 2010 (right). (bottom panels) Corresponding land cover maps: dark green = "Tree Cover", bright green = "Tree Cover Mosaics", orange = "Other Wooded Land", white = "Other Land", dark grey = Cloud, Smoke; blue = "Water".

\subsection{Qualitative information on change patterns and on causes of change}

We screened our satellite imagery for dominant patterns of forest change (2000-2010) visible within our sample units, aiming to complement our quantitative assessment. The dominant patterns identified relate to (i) forest conversion, (ii) logging (canopy openings and logging roads), (iii) replacement of natural forests by forest plantations, (iv) afforestation or re-forestation, (v) shifting cultivation and (vi) others, including new infrastructure (roads, dams) or burnings. Patterns of small and dispersed change were neglected. In case of no visible change for 2000-2010 we documented also striking change patterns of the period 1990-2000.
We further compare the output of two expert consultations on main processes and causes of forest change in Southeast Asia, held for both continental and insular Southeast Asia (Stibig et al., 2007b). During these consultations we compiled in the regional context information on major ongoing processes of forest change, based on the knowledge of national and regional forestry experts, identifying the approximate location and extent of the areas mostly concerned. The objective of the consultation was to collect information that could support our remote sensing assessment. The consultation also permitted us to consider change processes in the very early stages or of still moderate intensity, not visible through satellite remote sensing, and therefore adding a 
forward-looking component on change to be expected at very high likelihood.

\subsection{Accuracy assessment}

For estimating the accuracy of our results we implemented a consistency assessment by comparing our results to a proxy reference data set, which was obtained through a careful labelling of a subset of mapping units (polygons) by an independent interpreter with good regional expertise. A strict accuracy assessment based on field data or reference imagery of very high resolution was not feasible in view of the extensive coverage of historical data from 1990 and 2000 to be evaluated. As demonstrated over dry and humid ecosystems in Africa and for South America (Eva et al., 2012; Bodart et al., 2013; Ernst et al., 2013) this approach provides a measure of the overall consistency of the methodology, indicating the variability inherent in the remote sensing interpretation and mapping approach. For this consistency assessment, a randomly selected subsample of sites (101 from the total sample of 418 sites) is taken as primary sampling units (PSU). A systematic dot grid of $81(9 \times 9)$ dots with a $1 \mathrm{~km}$ distance between the dots is positioned over each PSU. All polygons coinciding with the central point or the four corners points of the dot grid are selected as secondary sampling units (SSU). As additional SSU selection, from the remaining 76 points of the dot grid all polygons that display a change in tree cover in either of the two periods 1990-2000 or 2000-2010 are selected. In total 1572 polygons (SSUs) were selected and labelled by an independent interpreter into the main land cover categories ("Tree Cover", "Tree Cover Mosaic", "Other Wooded Land" and "Other Land Cover"). The results of this independent interpretation were then compared to the original mapping results.

\section{Results}

\subsection{Status and change of forest cover in Southeast Asia}

In total, the forest-covered area of Southeast Asia (incl. PNG (Papua New Guinea) and the Solomon Islands) changed from 268.0 Mha in 1990 to 236.3 Mha in 2010 (Table 2). The total net loss of tree cover was $17.5 \mathrm{Mha}$ in the $1990 \mathrm{~s}$, and 14.5 Mha in the 2000s, which corresponds to annual change rates of $0.67 \%$ and $0.59 \%$, respectively (Table 3). At the same time, the land area covered by other wooded land (OWL, incl. oil palm) increased during these two periods by about 10.6 Mha and 7.1 Mha, respectively.

The forest covered area of continental Southeast Asia makes up almost one-third of Southeast Asia's forested area, displaying for the 1990s and 2000s annual rates of forest loss of 0.21 Mha and 0.48 Mha, respectively (Table 3). Insular Southeast Asia holds more than two-thirds of the regional forest cover, however, having faced high rates of annual forest loss of about 1.51 Mha in the 1990s and 0.96 Mha in the
Table 2. Forest cover and change from 1990 to 2010 in Southeast Asia $^{\mathrm{a}}$ (areas in Mha).

\begin{tabular}{lrrr}
\hline & STATUS & $\begin{array}{r}\text { Change } \\
1990-2000 \\
\text { Area (se) }\end{array}$ & $\begin{array}{r}\text { Change } \\
2000-2010 \\
\text { Area (se) }\end{array}$ \\
\hline Forest cover 1990 & $268.0(6.6)$ & & \\
Forest cover 2000 ${ }^{\mathrm{b}}$ & $250.6(6.7)$ & & \\
Forest cover 2010 & $236.3(6.7)$ & & \\
Gross forest cover loss & & $20.4(1.9)$ & $17.7(1.9)$ \\
Gross forest cover gain & & $2.9(0.5)$ & $3.2(0.7)$ \\
\hline Net change forest cover & & $-17.5(2.6)$ & $-14.5(2.5)$ \\
Net change OWL & & $+10.6(1.8)$ & $+7.1(1.6)$ \\
\hline
\end{tabular}

a incl. PNG \& Solomon Isl., ${ }^{\mathrm{b}}$ average from two period estimates, ${ }^{\mathrm{c}}$ OWL $=$ Other Wooded Land.

2000s (Table 3). Although the sampling strategy used in this study has been designed for regional scales, a country estimate may be given for Indonesia (incl. East Timor), which holds almost two-thirds of the forest area and also of the sample units (156) of insular Southeast Asia. According to this study, the forest-covered area of Indonesia decreased from 123.8 Mha in 1990 to 104.4 Mha in 2010 (Table 3), with high rates of annual forest loss of $1.15 \mathrm{Mha}(0.98 \%)$ and $0.82 \mathrm{Mha}$ (in $0.76 \%$ ) in the 1990s and 2000s, respectively. Deforestation in Indonesia contributed therefore almost $80 \%$ to the sub-regions forest loss (incl. PNG and Solomon Islands).

The spatial distribution of forest cover losses of the last two decades across the region shows concentration on the islands of Sumatra and Borneo, as well as on the lower Mekong Basin (Fig. 3). In continental Southeast Asia there is indication of increased forest cover loss along the Annamite mountain range (Laos, Cambodia and Vietnam), and in the border zones of Cambodia (with Thailand and Vietnam) and of northern Myanmar. Gains in forest cover are found for instance in parts of Vietnam. In insular Southeast Asia the spatial change pattern remains quite similar for both decades. The high pressure on the lowland and peat swamp forests of Sumatra has remained, on Borneo there are signs of expansion of forest cover loss towards the centre and the north. Forest cover gain in central Sarawak in 2010 is rather related to the management cycle of forest plantations. In comparison, forest cover loss has been assessed to be lower on the islands of Sulawesi and New Guinea. However, there might be change in forest canopies and structure due to selective logging, which is not reflected as change in forest area. In both sub-regions there are change locations close to or coinciding with protected areas.

\subsection{Patterns of forest change types as identified from satellite imagery}

The regional overview of the most prevailing forest change type patterns visible from satellite imagery within the sample sites (Fig. 4) shows the following: (i) patterns of forest 


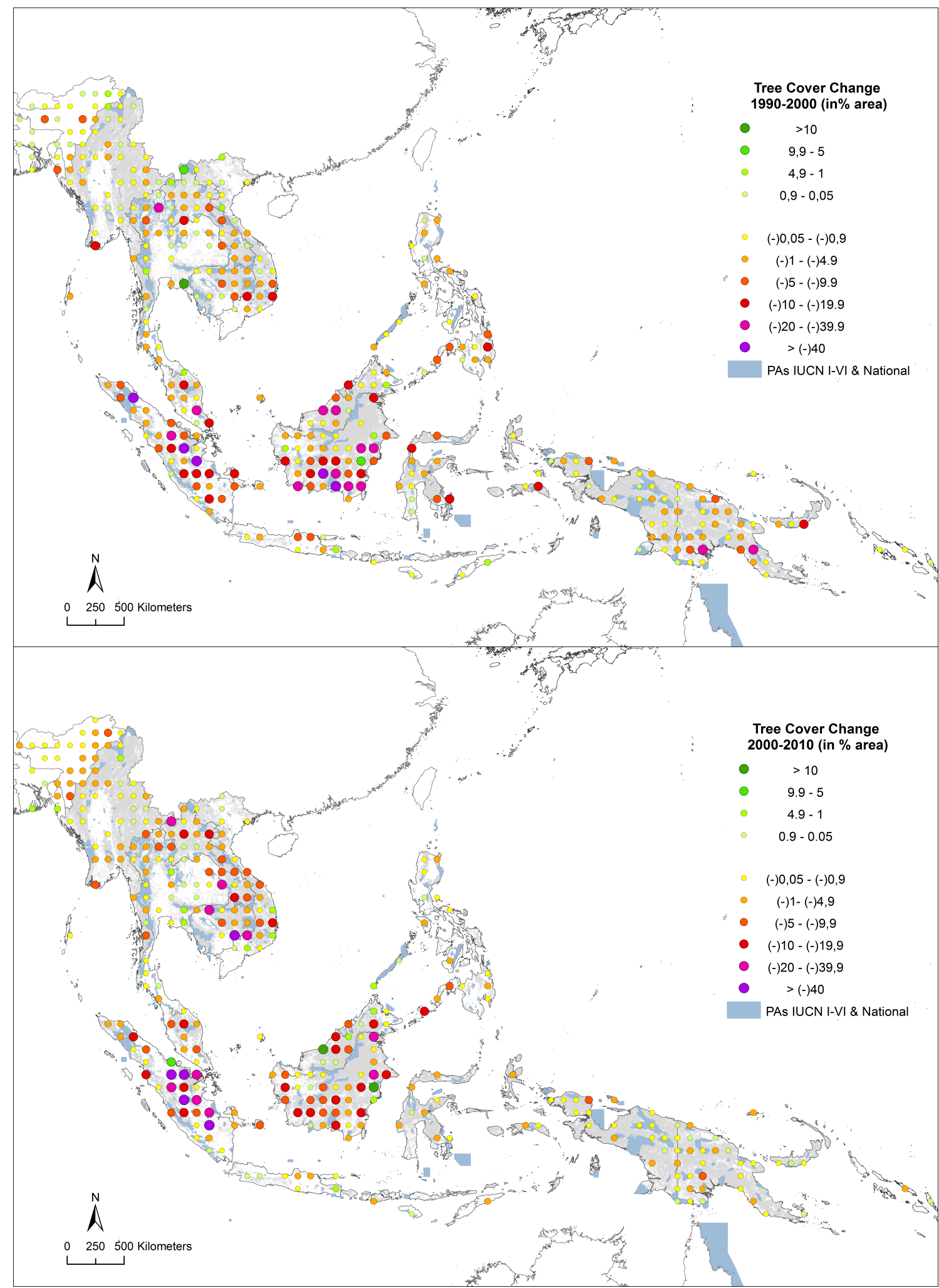

Fig. 3. Spatial distribution of forest cover change in Southeast Asia: change in forest cover per sample site (in $\%$ of land area, clouds excluded). IUCN I-VI and National Protected Areas from IUCN and UNEP (2009). Background map (grey): Forest Cover 2000. 
Table 3. Forest cover and annual change in Southeast Asia and sub-regions (areas in Mha).

\begin{tabular}{|c|c|c|c|c|c|}
\hline \multirow[t]{3}{*}{ Sub-region } & \multicolumn{3}{|c|}{ Forest Cover } & \multirow{2}{*}{$\begin{array}{r}\text { Annual net change } \\
1990 \mathrm{~s}\end{array}$} & \multirow{2}{*}{$\begin{array}{r}\text { Annual net change } \\
2000\end{array}$} \\
\hline & 1990 & $2000^{\mathrm{a}}$ & 2010 & & \\
\hline & Area & Area & Area & Area (se); Change $\%$ (se) & Area (se); Change $\%$ (se) \\
\hline SE-Asiab & 268.0 & 250.6 & 236.3 & $1.75(0.26) ; 0.67(0.10)$ & $1.45(0.25) ; 0.59(0.10)$ \\
\hline Continental SE-Asia & 78.7 & 76.5 & 71.7 & $0.21(0.08) ; 0.27(0.10)$ & $0.48(0.13) ; 0.65(0.18)$ \\
\hline Insular SE-Asia ${ }^{b}$ & 187.9 & 173.0 & 163.5 & $1.51(0.25) ; 0.84(0.14)$ & $0.96(0.22) ; 0.57(0.13)$ \\
\hline Indonesia $^{\mathrm{c}}$ & 123.8 & 112.4 & 104.4 & $1.15(0.25) ; 0.98(0.21)$ & $0.82(0.21) ; 0.76(0.19)$ \\
\hline
\end{tabular}

${ }^{\mathrm{a}}$ average from two period estimates, ${ }^{\mathrm{b}}$ incl. PNG \& Solomon Isl., ${ }^{\mathrm{c}}$ including East Timor.

conversion to non-forest land have been observed most frequently across the region, particularly on Sumatra and Borneo, and in the eastern Mekong Basin (Laos, Cambodia, Vietnam border zone), for the most part linked to locations of high forest cover loss in our quantitative analysis (Fig. 3). The conversion patterns in the lowlands of Sumatra and Borneo could be frequently related to the presence of oil palm plantations. (ii) Logging patterns were identified in sites in eastern Sumatra, in the east of Sarawak and in Sabah, as well as in central and north-eastern Borneo. On New Guinea logging patterns were visible for a limited number of sites. However, logging is not necessarily reflected by a loss of forest area in our quantitative assessment (e.g. change from "Tree Cover" to "Tree Cover Mosaic"). (iii) The replacement of natural forest cover by forest plantations could be observed for sites in Cambodia, on Peninsular Malaysia, on Sumatra and in Sarawak. (iv) Shifting cultivation mosaics stretch particularly across the north of continental Southeast Asia (northern Laos and Thailand, Myanmar), but were not perceived as a major factor of forest loss in the regional context. Typical examples of change patterns in Southeast Asia are displayed in Figs. 5 and 6, including (i) the massive expansion of agricultural areas, (ii) the conversion of lowland forests to oil palm plantations, (iii) the establishment of fastgrowing tree plantations for pulp and paper production, (iv) burned areas, (v) logging, (vi) agricultural expansion and establishment of rubber plantations, (vii) shifting cultivation, and (viii) the conversion of mangrove forests to aquaculture (Figs. 5 and 6).

\subsection{Accuracy assessment}

Based on the systematically selected set of the mapping units (five polygons located at the corners and centre of the dot grid) the overall agreement between our mapping results and the results from independent interpretation is $85 \%, 85 \%$ and $91 \%$ for the years 1990, 2000 and 2010, respectively (overall average agreement for the three categories "Tree Cover", "Tree Cover Mosaic" and all other land cover) (Table 4). We found lower agreement for the single category "Tree Cover Mosaic", ranging between $50 \%$ and $71 \%$ and reflecting the difficulty to clearly define tree cover proportions from the remote sensing data used. Considering "change" polygons only, the overall agreement in terms of class area was $74 \%$, $65 \%$ and $72 \%$, respectively (Table 4 ). The higher uncertainty in mapping change is due to the fact that most change polygons are of smaller size, and the decision on mapping a change cannot always be done unambiguously. However, given the fragmented landscapes and the seasonal variability of forest phenology in Southeast Asia we consider the overall agreement and mapping consistency as satisfying, providing a good indication of the achievable mapping accuracy.

Differences between the two sub-regions are considered to be related to the main forest types. The level of agreement in mapping the mainly evergreen humid tropical forests of the insular sub-region is notably higher than that for the predominantly mixed and dry deciduous forests on the continent (Table 4), reflecting the complexity of mapping the seasonal forest formations of continental Southeast Asia.

\section{Discussion}

Our study provides an updated and uniform regional view on extent and change of forest cover in Southeast Asia, making best possible use of available satellite remote sensing data. The results show a drop of the total forest cover of Southeast Asia from $\sim 268$ Mha in 1990 to $\sim 236$ Mha in 2010. This corresponds to a forest cover loss of $\sim 32$ Mha $\left(\sim 320000 \mathrm{~km}^{2}\right)$ in only $20 \mathrm{yr}$, an area comparable to the size of Vietnam or about $6.5 \%$ of the regions total "land" area.

Referring to the quantitative results, there are only few studies one can compare to at regional levels. Most widely used is the database compiled by the FAO Forest Resources Assessment (FRA2010), based on country reporting and national forest inventories (FAO, 2010). The regional aggregation of these data results in "forest areas" of 281 Mha and 245 Mha for 1990 and 2010, respectively, both higher than our regional estimates of "forest cover". Several factors can be responsible for such difference: Firstly, the definitions of "forest cover" and "forest area" are not completely identical, as we do not consider aspects of "dominant land use" and "potential tree growth", contrary to FAO. Secondly, the aggregation of national figures to regional levels 


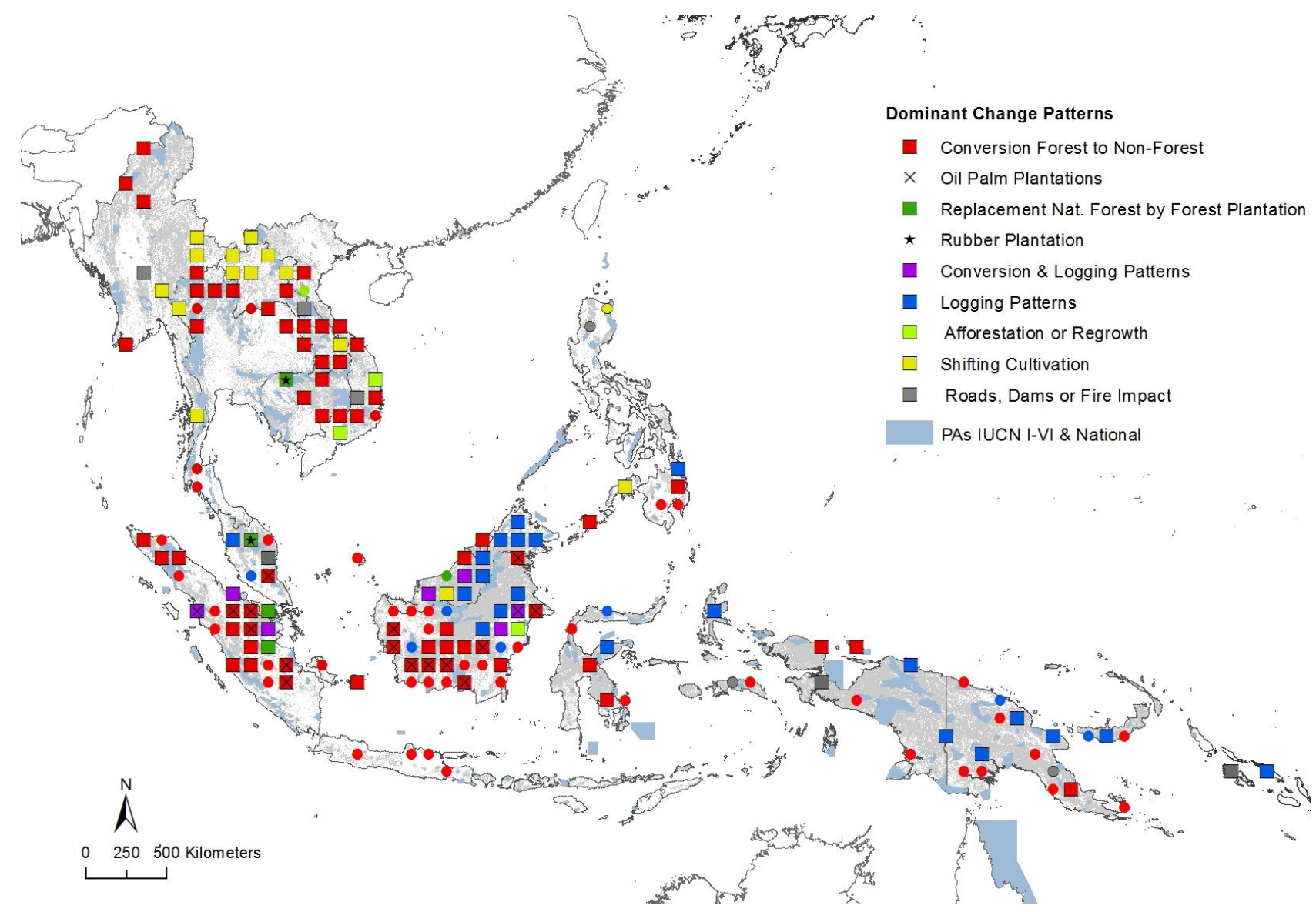

Fig. 4. Dominant patterns of forest change types as visually identified from satellite imagery within the sample units. Squares: 2000-2010 patterns. Circles: 1990-2000 patterns. Background map (grey): Forest Cover 2000.

Table 4. Result of overall accuracy assessment as percentage of agreement between different interpreters (comprising categories "Tree Cover", "Tree Cover Mosaic", "Other Land").

\begin{tabular}{|c|c|c|c|c|c|c|c|c|c|}
\hline & \multicolumn{3}{|c|}{$(\mathrm{I})^{*}$} & \multicolumn{3}{|c|}{ (II)* } & \multicolumn{3}{|c|}{$(\mathrm{IIII})^{*}$} \\
\hline & Cont. SEA & Insular SEA & All SEA & Cont. SEA & Insular SEA & All SEA & Cont. SEA & Insular SEA & All SEA \\
\hline No polygons & (185) & (320) & (505) & (308) & (759) & (1067) & (493) & (1079) & (1572) \\
\hline 1990 & 79 & 86 & 85 & 58 & 75 & 74 & 69 & 78 & 77 \\
\hline 2000 & 83 & 86 & 85 & 63 & 65 & 65 & 73 & 71 & 71 \\
\hline 2010 & 81 & 94 & 91 & 69 & 72 & 72 & 75 & 78 & 77 \\
\hline
\end{tabular}

* polygon selection: (I) systematic polygon selection; (II) additional change polygons; (III) all polygons.

holds uncertainties difficult to quantify, the error levels of the individual assessments are unknown and there are differences in methods, definitions and reference dates. Thirdly, our remote-sensing-based forest mapping approach tends to classify tree cover of heights just above the $5 \mathrm{~m}$-class definition threshold still to "Other Wooded Land" due to the similar spectral characteristics. National assessments may report these areas as "forest area", explaining therefore to some extent lower area estimates by our study.

At sub-regional levels, this study estimates annual forest cover loss of continental Southeast Asia at $0.21 \mathrm{Mha}$ and 0.48 Mha for the $1990 \mathrm{~s}$ and $2000 \mathrm{~s}$, respectively (Table 3), whilst the corresponding FAO figures are $0.47 \mathrm{Mha}$ and $0.33 \mathrm{Mha}$. The discrepancies in change and its temporal distribution could not be put down to a specific reason. Increased forest loss has also been reported for the 20002010 period for Cambodia and Laos by FAO (FAO, 2010). However, we do not include in "tree cover" areas of recent forest plantation, as reported of large extent in Vietnam (FAO, 2010), therefore increasing our 2000-2010 change estimate. In addition, forest-non forest transitions in seasonal dry forests (e.g. in Myanmar) were sometimes difficult to 


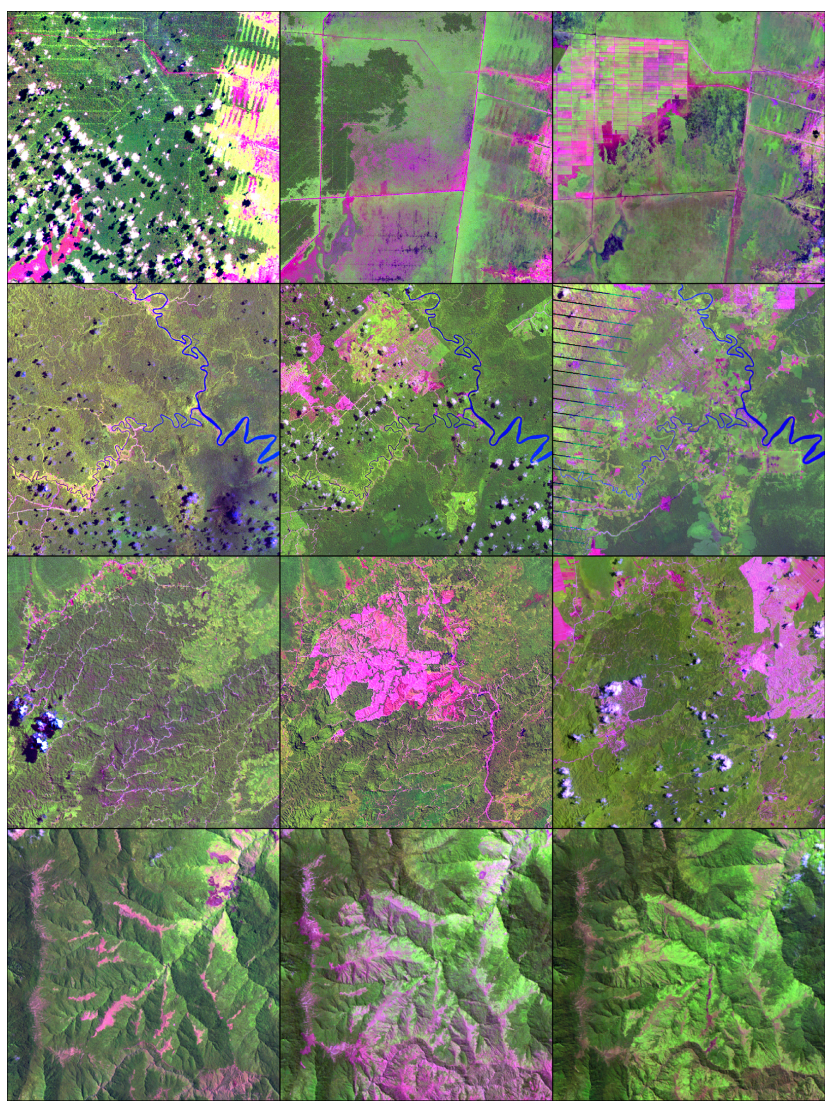

Fig. 5. Examples of forest change patterns from insular Southeast Asia, taken from Landsat TM/ETM imagery for 1990-2000-2010 for selected sample units. Top row, site S03-E114, S-Kalimantan: conversion of former peat swamp forest to agriculture and oil palm; row 2, site N04-E117, N. Kalimantan: conversion of lowland forests to oil palm plantations; row 3, site N03-E113, N. Sarawak: plantation establishment of fast-growing trees for pulp and paper; bottom row, site S08-E147, PNG: impact of fires.

detect from satellite imagery because of open canopies, effects of leaf shedding and impact of burning. It is therefore possible that some forest change, already present in the period 1990-2000 but not clearly detectable as such, could then be clearly classified on the 2010 data set, increasing the 2000-2010 change only.

For insular Southeast Asia there are obvious differences for Indonesia: our estimates of annual forest cover loss for the 1990s and 2000s are 1.15 Mha and 0.82 Mha (Table 3), compared to FAO figures ("forest land") of 1.93 Mha and 0.51 Mha, respectively. A review of our sample sites did not explain these differences. For the period 2000-2010 our annual forest cover change estimate is rather in the range of those from other remote sensing studies, with $0.71 \mathrm{Mha}$ for the period 2000-2005 (Hansen et al., 2009) or 0.88 Mha for the period 2000-2010 (Miettinen et al., 2011). Referring to the change in the 1990s, our sample may not have fully captured the impact of the 1997/1998 fires, however, the diffi-

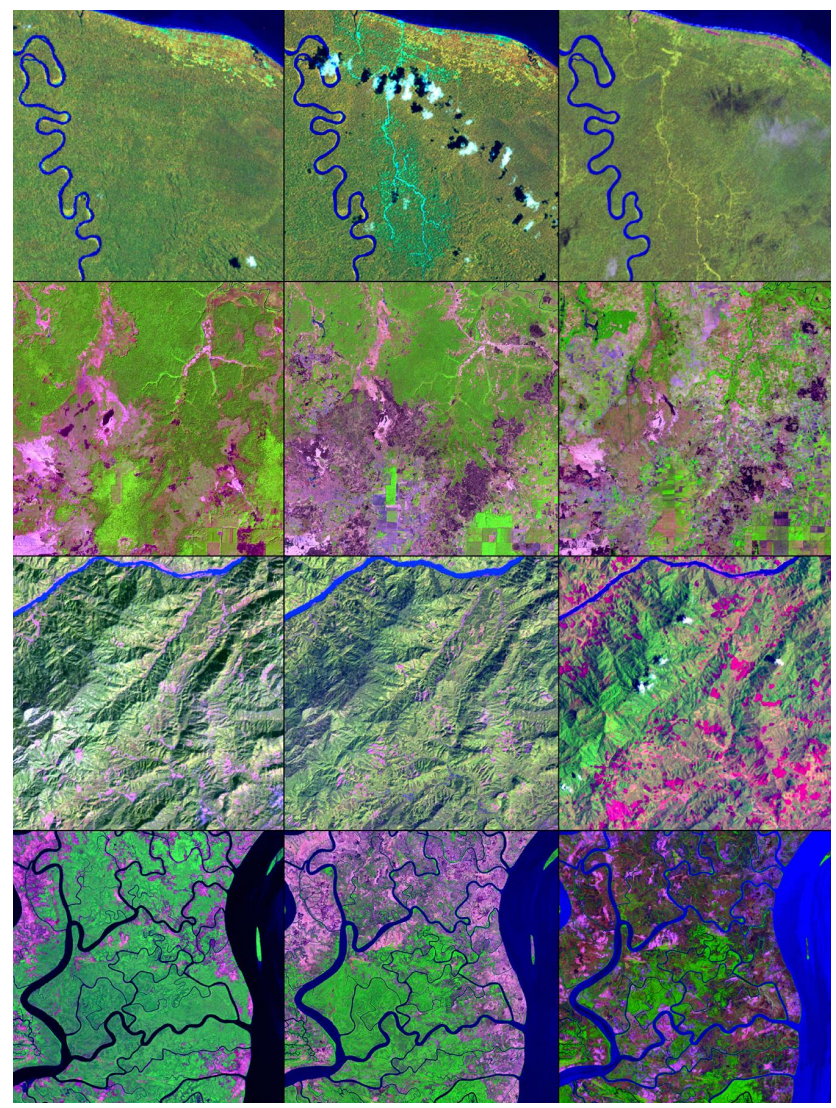

Fig. 6. Examples of forest change patterns from Papua and continental Southeast Asia (Cambodia, Laos and Myanmar), taken from Landsat TM/ETM imagery for 1990-2000-2010 for selected sample units. Top row, site S02-E139, Papua/Indonesia: logging; row 2, site N12-E106, Cambodia: agricultural expansion and rubber plantations; row 3, site N20-E102, Laos: shifting cultivation; bottom row, site N16-E095, Myanmar: mangrove forest conversion for aquaculture.

culty in accurately assessing forest cover destroyed by these fires might also have led to an overestimate of forest loss by national figures, resulting in a lower change figure for the following decade.

Putting our results in the context of the "regional pattern of change processes" established through expert consultation (Fig. 7), one can perceive that change processes affect forest areas larger than seen from remote sensing only. The main forest change processes in Southeast Asia were identified by the experts as follows (Fig. 7):

1. The conversion of forests to cash crop plantations has been considered the main cause of forest loss in Southeast Asia. This is also supported by the change patterns identified from satellite imagery within our sample sites (Fig. 4). Main cash crops include in continental Southeast Asia coffee (e.g. S-Laos, central highlands Vietnam), tea (e.g. N. Thailand, Yunnan border area), sugar cane (e.g. N. Laos) as well as oil palm 


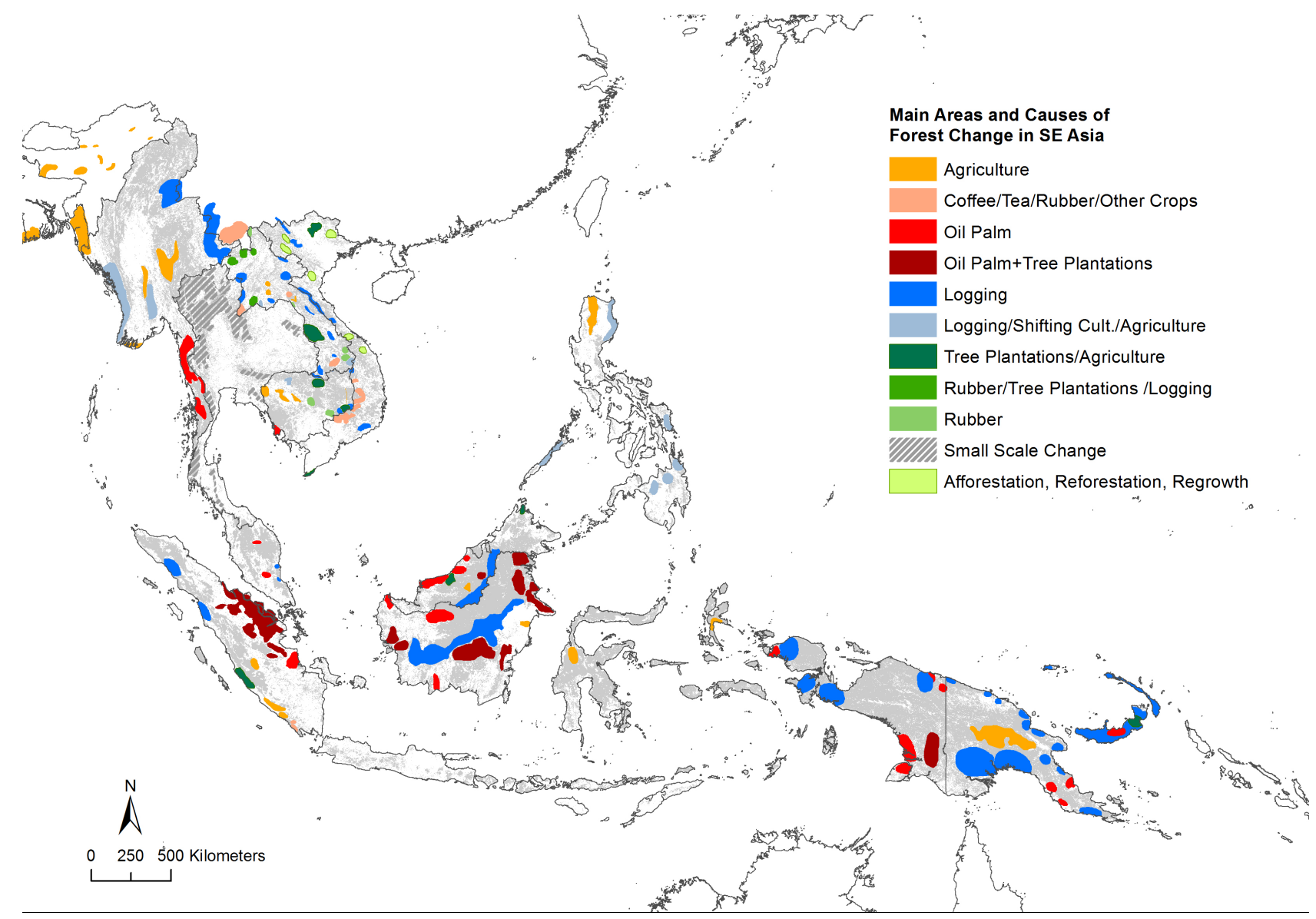

Fig. 7. Regional pattern of main areas and causes of forest change in Southeast Asia, as identified by expert consultation. Background map (grey): Forest Cover 2000.

(e.g. S-Myanmar). For insular Southeast Asia the highest impact has been seen in the expansion of oil palm plantations, often on peat land, and mainly in eastern Sumatra, coastal Sarawak, central and northeast Kalimantan and southeast Papua, but also starting in Papua New Guinea.

2. Non-sustainable logging has been considered a second important factor of change, potentially resulting in forest degradation and initiating conversion processes. On the continent logging is an issue along the Annamite mountain range (Laos, Vietnam, Cambodia) as well as in northern Myanmar, in insular Southeast Asia in eastern Sarawak, central Kalimantan and New Guinea. The logging indications for New Guinea include areas of low-intensity logging, where stronger impacts may be expected in the long term. They may be taken as indicative for the island becoming a new focus for timber logging, moving away from Sumatra and Borneo. In a number of cases local experts classified logging as "illegal" and affecting protected areas, for both continental and insular Southeast Asia, although the level of recent illegal logging in the insular sub-region was judged to be lower than in the previous decade. From satellite imagery we could not detect logging patterns in all areas marked by the expert consultation, particularly for continental Southeast Asia and on New Guinea (Fig. 4). On the continent indications of logging are less visible from satellite imagery in already fragmented, deciduous and frequently already logged-over forests. On New Guinea logging patterns were not depicted in areas of low-intensity logging and when logging road networks were missing. Furthermore, canopies in evergreen forests can quickly close after moderate intervention.

3. The replacement of natural forests by fast-growing forest plantations (e.g. Acacia mangium on Sumatra and Borneo) and by rubber plantations (e.g. in Cambodia, Laos and Thailand) has been ranked third in terms of importance for forest change in Southeast Asia.

4. At local levels important causes for change further include fires (e.g. Indonesia, Thailand), mining (e.g. 
Indonesia, Laos), urbanization (Myanmar), construction of hydropower dams (e.g. Mekong Basin), road construction (e.g. Laos, Cambodia), shrimp farming (mangrove areas), fuel wood collection (Myanmar, Thailand, Vietnam), migration of ethnic groups (e.g. Myanmar) and resettlements (e.g. Laos). The impact of shifting cultivation (e.g. Myanmar, Laos) has been classified as "secondary" in the context of regional forest loss and compared to its role in the pre-1990s.

In conclusion, the magnitude of forest change in Southeast Asia over the last two decades as well as the indications on active change processes do not only show the pressure on the region's remaining forests, but call for regional concepts of sustainable forest management and forest protection. This is not only for preserving some of the remaining intact tropical forests of Southeast Asia and for maintaining regional biodiversity, but also in order to deliver the forest and environmental services needed by a growing population.

\section{Supplementary material related to this article is available online at http://www.biogeosciences.net/11/247/ 2014/bg-11-247-2014-supplement.pdf.}

Acknowledgements. We are grateful for having received the vast majority of Landsat satellite data from the United States Geological Survey (USGS). We are thankful for the support of the CEOS LSI Constellation team (US), and of ACRES (Australia), GISTDA (Thailand) and SPOT IMAGE (France) for providing additional satellite imagery from 1990 and 2000. We thank the European Space Agency (ESA) for providing 2010 imagery (AVNIR, KOMPSAT) in the context of the TROPFOREST project, and GISTDA (Thailand) for providing $2010 \mathrm{TM}$ imagery from the Thai receiving station.

We would like to thank all the experts from national forestry institutions in Southeast Asia and PNG for their support in reviewing and "validating" the TREES mapping results in the context of regional workshops: S. Sophyra, L. Chivin and P. Sam (Forestry Adm. Cambodia), K. Chanthalasy, B. Luangphaseuth, H. Khamma and S. Siboun (Forestry Dep. Laos),. San San Aye, A. Aung Myint, P. Htut, and U. A. Myo Win (Forest Dep. Myanmar), S. Punkul (Royal Forest Dep. Thailand), Y. Jantakat (Suranaree Uni. Thailand), N. Phu Hung, L. Anh Hung and M. V. Tinh (FIPI, Viêt Nam), J. Wong-Basiuk (Sarawak Forestry Dep., Malaysia), J. A. Ignacio (ESSC, Philippinnes), R. Sari and Mr. Budiharto (MoF, Indonesia), A. Wijaya (CIFOR, Indonesia), and J. Pokana (Office of Climate Change, PNG).

We are further grateful for the support of regional experts for identifying regional patterns and drivers of forest change in the context of two sub-regional workshops in Jakarta and Vientiane in 2007: V. Ambia (Forest Authority, PNG), M. Boccucci (World Bank, Indonesia), R. Dennis (CIFOR / SEKALA, Indonesia), D. Gaveau (WCS, Indonesia), M. Jaeger (EC- FLEGT, Indonesia), E. Meijaard, (Nature Conservancy, Indonesia), Y. K.
D. Muliastra (SEKALA, Indonesia), J. Schade, (DFS, Germany), F. Siegert (RSS, Germany), F. Stolle (WRI, US), Ib. K. Wedestra (EC- FLEGT, Indonesia), J. B. Weingart (Leyte State Univ., Philippines), J. Wong (Sarawak Forest Dep., Malaysia), Y. H. Yap (Forest Dep., Malaysia).

S. Bhumibhamon (Mae Fah Luang University, Thailand), N. Cox (WWF, Mekong Basin), P. M. Cuong (FIPI, Viêt Nam), C. Feldkötter (GIZ, Laos), C. Inthavong (Dep. Land Use Planning, Laos), S. Jaenne (World Bank, Laos), H. Khamma (Dep. Forestry, Laos), C. MacAlister (MRCS), T. A. Moe (UNEP RRC.AP Thailand), T. Ngwe (Forest Dept., Myanmar), A. Rasphone (MRCS, Laos), H. Rath (MRCS, Laos), F. Rock (GIZ, Laos), S. Teang (Forestry Adm., Cambodia), R. B. Tennent (GFS, Cambodia), V. A. Tuan (VTGEO, Vietnam), W. Wisesjindawat (MRCS, Laos).

Edited by: M. Williams

\section{References}

Achard, F., Eva, H., Stibig, H.-J., Mayaux, P., Gallego, J., Richards, T., and Malingreau, J.-P.: Determination of deforestation rates of the world's humid tropical forests, Science, 297, 999-1002, 2002.

ALOS: K and C Mosaic Homepage, ALOS research and application project, Japan Aerospace Exploration Agency (JAXA) and the Ministry of Economy, Trade and Industry (METI), Japan: http:// www.eorc.jaxa.jp/ALOS/en/kc_mosaic/kc_mosaic.htm, (last access: 14 June 2013), 2010.

Beuchle, R., Eva, H., Stibig, H.-J., Bodart, C., Brink, A., Mayaux, P., Johansson, D., Achard, F., and Belward, A.: A satellite data set for tropical forest area change assessment, Int. J. Remote Sens., 32, 7009-7031, 2011.

Bodart, C., Eva, H., Beuchle, R., Raši, R., Simonetti, D., Stibig, H.-J., Brink, A., Lindquist, E., and Achard, F.: Pre-processing of a sample of multi-scene and multi-date Landsat imagery used to monitor forest cover changes over the tropics, ISPRS J. Photogramm., 66, 555-563, 2011.

Bodart, C., Brink, A. B., Donnay, F., Lupi, A., Mayaux, P., and Achard, F.: Continental estimates of forest cover and forest cover changes in the dry ecosystems of Africa between 1990 and 2000, J. Biogeogr., 40, 1036-1047, 2013.

Bucki, M., Cuypers, D., Mayaux, P., Achard, F., Estreguil, C., and Grassi, G.: Assessing REDD+ performance of countries with low monitoring capacities: the matrix approach, Environ. Res. Lett., 7, 014031, doi:10.1088/1748-9326/7/1/014031, 2012.

Donato, D. C., Kauffman, J. B., Murdiyarso, D., Kurnianto, S., Stidham, M., and Kanninen, M.: Mangroves among the most carbonrich forests in the tropics, Nat. Geosci., 4, 293-297, 2011.

ESA: TROPFOREST: http://www.tropforest.info/, (last access: 14 June 2013), 2013.

Ernst, C., Mayaux, P., Verhegghen, A., Bodart, C., Christophe, M., and Defourny, P.: National forest cover change in Congo Basin: deforestation, reforestation, degradation and regeneration for the years 1990, 2000 and 2005, Glob. Change Biol., 19, 1173-1187, 2013.

Eva, H. D., Achard, F., Beuchle, R., De Miranda, E., Carboni, S., Seliger, R., Vollmar, M., Holler, W., Oshiro, O., Barrena, V., and Gallego, J.: Forest cover changes in tropical South and Central 
America from 1990 to 2005 and related carbon emissions and removals, Remote Sens., 4, 1369-1391, 2012.

FAO: Forest Resources Assessment 1990: Global Synthesis: FAO Forestry Paper 124, Food and Agriculture Organization of the United Nations, Rome, 1995.

FAO: Country Boundaries of the World (FGGD), Food and Agriculture Organization of the United Nations, Rome, 2007. (Available at: http://www.fao.org/geonetwork/srv/en/metadata.show? id=4039), (last access: 14 June 2013), 2013.

FAO: Global Forest Resources Assessment 2010: Main Report: FAO Forestry Paper 163, Food and Agriculture Organization of the United Nations, Rome, 2010.

FAO and JRC: Global forest land-use change 1990-2005: FAO Forestry Paper 169, Food and Agriculture Organization of the United Nations and European Commission Joint Research Centre, Rome, 2012.

Hansen, M. C., Stehman, S. V., Potapov, P. V., Arunarwati, B., Stolle, F., and Pittman, K.: Quantifying changes in the rates of forest clearing in Indonesia from 1990 to 2005 using remotely sensed data sets, Environ. Res. Lett., 4, 12 pp., 2009.

Harris, N. L., Brown, S., Hagen, S. C., Saatchi, S. S., Petrova, S., Salas, W., Hansen, M. C., Potapov, P. V., and Lotsch, A.: Baseline Map of Carbon Emissions from Deforestation in Tropical Regions, Science, 336, 1573-1576, 2012.

IUCN and UNEP: The World Database on Protected Areas (WDPA), United Nations Environment Programme - World Conservation Monitoring Centre (UNEP-WCMC), Cambridge, UK, 2009.

Lee, D. K.: Challenging forestry issues in Asia and their strategies, in: The Future of Forests in Asia and the Pacific: Outlook for 2020, Proceedings of an international conference on the outlook for Asia-Pacific forests to 2020, Chiang Mai, 16-18 October 2007 edited by: Leslie, R. N., Food and Agriculture Organization of the United Nations, Bangkok, 2009.

Mayaux, P., Holmgren, P., Achard, F., Eva, H., Stibig, H.-J., and Branthomme, A.: Tropical forest cover change in the 1990s and options for future monitoring, Philos. T. R. Soc. B, 360, 373-384, 2005.
Miettinen, J. and Liew, S. C.: Separability of insular Southeast Asian woody plantation species in the $50 \mathrm{~m}$ resolution ALOS PALSAR mosaic product, Remote Sens. Lett., 2, 299-307, 2011.

Miettinen, J., Shi, C., and Liew, S. C.: Deforestation rates in insular Southeast Asia between 2000 and 2010, Glob. Change Biol., 17, 2261-2270, 2011.

Page, S., Rieley, J. O., and Banks, C. J.: Global and regional importance of the tropical peatland carbon pool, Glob. Change Biol., 17, 798-818, 2011.

Raši, R., Bodart, C., Stibig, H.-J., Eva, H., Beuchle, R., Carboni, S., Simonetti, D., and Achard, F.: An automated approach for segmenting and classifying a large sample of multi-date Landsat imagery for pan-tropical forest monitoring, Remote Sens. Environ., 115, 3659-3669, 2011.

Raši, R., Beuchle, R., Bodart, C., Vollmar, M., Seliger, R., and Achard, F.: Automatic updating of an object-based tropical forest cover classification and change assessment, IEEE J. Sel. Top. Appl., 6, 66-73, 2013.

Stibig, H.-J., Belward, A. S., Roy, P. S., Rosalina-Wasrin, U., Agrawal, S., Joshi, P. K., Hildanus, Beuchle, R., Fritz, S., Mubareka, S., and Giri, C.: A land-cover map for South and Southeast Asia derived from SPOT-VEGETATION data, J. Biogeogr., 34, 625-637, 2007a.

Stibig, H.-J., Stolle, F., Dennis, R., and Feldkötter, C.: Forest Cover Change in Southeast Asia - The Regional Pattern, EURScientific and Technical Research Series, EUR 22896 EN, Office for Official Publications of the European Communities, Luxembourg, 41 pp., $2007 \mathrm{~b}$.

USGS: Earth Explorer: http://earthexplorer.usgs.gov/, (last access: 14 June 2013), 2013.

van der Werf, G. R., Morton, D., DeFries, R., Olivier, J., Kasibhatla, P., Jackson, R., Collatz, G., and Randerson, J.: $\mathrm{CO}_{2}$ emissions from forest loss, Nat. Geosci., 2, 737-738, 2009. 